\title{
Electrical Machining at Nottingham: A Short History
}

\author{
Adam T. Clare*, James W. Murray, Alistair Speidel, Ivan Bisterov \\ * Advanced Component Engineering Laboratory, Faculty of Engineering, University of Nottingham, UK
}

\begin{abstract}
Electrical machining remains an important area of industrial activity and research in the UK. Historically, British universities have made notable contributions which have helped to shape the state-of-the-art. There is also a healthy network of machine makers and machine users in the UK which support the stalwart aerospace industry. This paper briefly introduces the UK electrical machining microcosm and then focuses on the electrical discharge and electrochemical machining contributions made at the University of Nottingham since 2010. The paper introduces the people and their ideas alongside the collaborations that have made this work possible.
\end{abstract}

\section{INTRODUCTION}

The authors were invited to contribute to the IJEM by Prof. Akira Okada (Okayama University) to provide an overview of activities at the University of Nottingham in relation to our progress in electrical machining techniques. Given the strong affinity we share with numerous friends and colleagues in Japan, we were only too happy to accept this invitation and share with IJEM readers some details of our progress in recent years and explore the context for electrical machining in the UK.

In considering Nottingham's contributions it is perhaps first useful to consider wider historical researcher activity in the UK. Key players in electrical machining (across ECM, EDM and variants) who have made outstanding contributions include University of Edinburgh (Prof. Joe McGeough), University of Birmingham (Prof. David Aspinwall, Dr Sein Leung), University of Manchester (Prof. Sri Hinduja), Cardiff University (Dr Samuel Bigot, Dr Emmanuel Brousseau) among others.

Figure 1 shows a recent timeline of contributions across the search terms of EDM and ECM. It also includes a summary of contributors since 1989 .

While the surge in high quality contributions from China continues to develop it is clear that colleagues in the UK continue to add value to our community and support the development of electrical machining. Reassuringly, contributions have been made across several scholars at different universities ensuring that university-based research in this area is robust. The authors are privileged to belong to this community.

Commercial activity in electrical machining approaches is also in good health, driven by the gas turbine market (both land based and aerospace). The need for the precision, high throughput and excellent surface condition associated with electrical machining processes in the production of aerospace components has fostered our research topic in the UK.

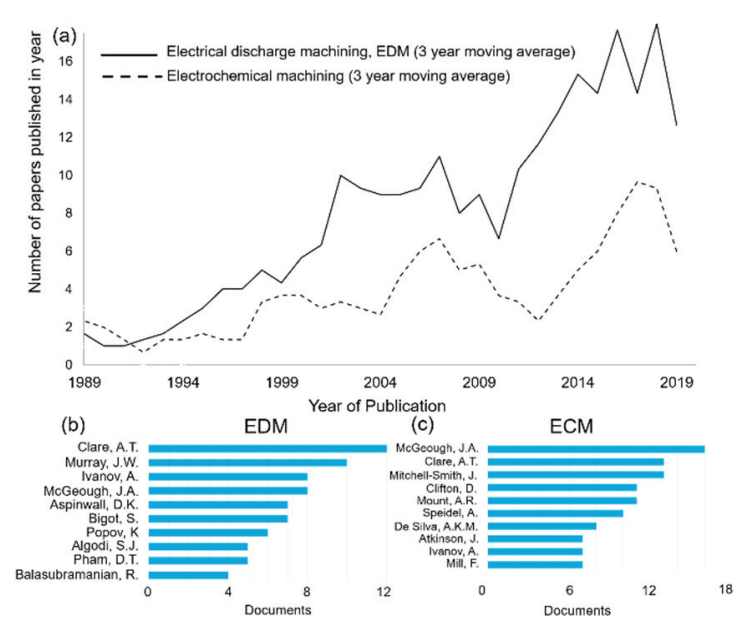

Figure 1 (a) A 3 year moving average plot showing the number of papers published in the UK only relating to EDM and ECM. (b) contributing authors in the UK in the field of ECM (c) contributing authors in the UK in the field of EDM. All data gathered from SCOPUS on 26/1/21 using the search terms highlighted in (a) dating back to 1989.

Multinational businesses such as Rolls-Royce (Derby), Siemens Turbomachinery (Lincoln) and IPT (Lincoln) are significant users of both electrochemical and electrical discharge methods for creating a range of features for high quality parts.

Typical examples would include the rapid drilling of cooling holes in turbine blades. UK based suppliers of such technology include Winbro (Coalville) and Tek4 (Leicester) who supply technology globally to the gas turbine market. The team at Nottingham has engaged widely with companies both providing and using electrical machining apparatus. This market remains buoyant despite changing habits in the aerospace market.

Like all manufacturing processes, research users of EDM and ECM technology in the UK are primarily 
concerned with high production rates at reduced cost while in particular maintaining premium material properties. These drivers have formed the basis of our work in supporting UK industry. When considering surface integrity, it is perhaps useful to consider our review on this topic ${ }^{1}$, which highlights the usage case for common processes and the resulting surface condition commonly observed.

Historically, Nottingham has been a centre for electrical machining research, specifically in ECM. For example, progress was made addressing challenges in ECM hole drilling methods ${ }^{2}$, as well as machinability of Ti-alloys ${ }^{3}$. This short paper will summarise our contributions made over the last 10 years, but it may be useful to consider the origin of our more recent activities.

In the winter of 2011, A.T Clare visited Prof. Masanori Kunieda (University of Tokyo) under the auspice of the Japan Society for Promotion of Science. This marked the start of a friendship which served to accelerate activity at Nottingham through partnership and collaboration. The kind support of Kunieda sensei allowed numerous PhD students (J.W Murray, A. Gasper, I. Bisterov) to have the opportunity to collaborate in Japan with outstanding researchers in the field of electrical machining. This has given rise to promising early careers researchers who are now beginning to flourish. Through this network the team at Nottingham has been able to build excellent partnerships with other researchers in the field including Profs. Koyano and Furumoto (Kanazawa University), Prof. Okada (Okayama University), Prof. Natsu (Tokyo University of Agriculture and Technology). Our team has also benefited greatly from conversation in the past with emeritus colleagues such as Prof. Masuzawa as well as Prof. Goto and Prof. Uno. We remain great admirers of the active research community in Japan and would welcome dialogue with colleagues. This paper is intended to serve as a map of our contributions and an invitation for further discussion and cooperation.

\section{ELECTRICAL DISCHARGE METHODS}

\subsection{Machining}

10 years of EDM at Nottingham has enabled progress to be made in both fundamental and applied research, expanding the applications and utility of EDM.

It was clear, and still is, that the role of debris in EDM is vital in stabilising machining ${ }^{4,5}$, however, the movement of debris between electrodes was not well understood. As well as playing a role in discharge location, debris movement is clearly critical for avoidance of, or in some cases deliberate contamination of, material onto both electrodes.

Our first work in this area elucidated the role of secondary discharges (i.e. unintended sparking) in

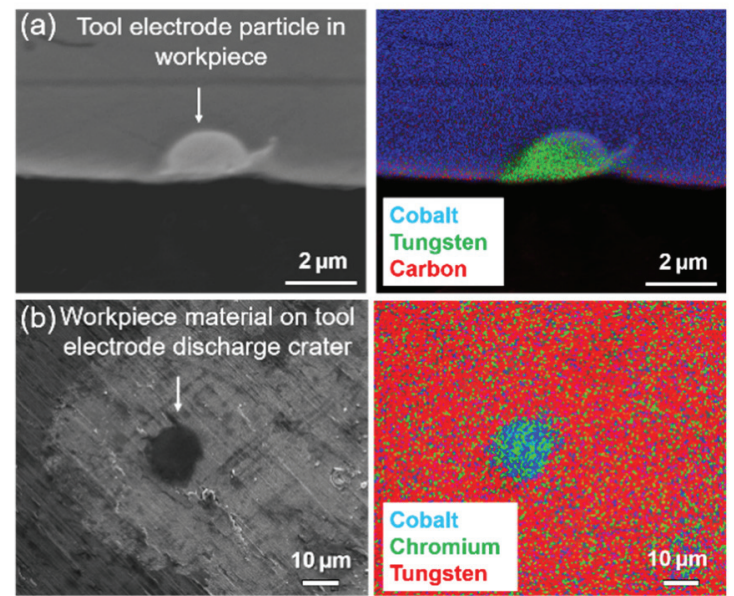

Figure 2 (a) Tungsten tool electrode material deposited while solid in workpiece surface, (b) Deposition of workpiece material on tool electrode due to secondary discharges ${ }^{6}$

machining as well as the role of debris in primary and secondary machining ${ }^{6}$. Figure 2 shows a partially melted deposit of tool electrode material in the surface of the workpiece, revealing it was deposited as a solid. A deposit of workpiece material high on the sides of the tool electrode, far from the machining zone revealed secondary discharges in this region are responsible for material movement from the dielectric onto the opposite electrode face. In addition, concentration of material was much higher in the centre/plasma zone of the discharge affected region.

The conclusions of this work were that deposition of workpiece material can play a key role in tool electrode geometry and wear mitigation, and that high melting point material can be deposited on the opposite electrode. Deposition of material predominantly, but not entirely, occurs in the plasmaaffected region of the discharge on the opposite electrode. Material movement and its dependence on conditions and parameters were used later at UoN to drive development of thin and thick electrical discharge coatings.

Having understood with greater detail the relationship between discharge and material movement, it became critical to understand the state of deposited material moved as a result of EDM to the opposite electrode, as well as the surrounding material. This arose from the increasing use of electrical discharge methods for coating at research and industrial levels, as well as the increasing requirement for high quality recast layers in machining, for example in the aerospace and semiconductor industries. In collaboration with Prof. Kunieda (University of Tokyo), we sought to obtain a fundamental understanding of the state of material deposited and modified by EDM, using transmission 


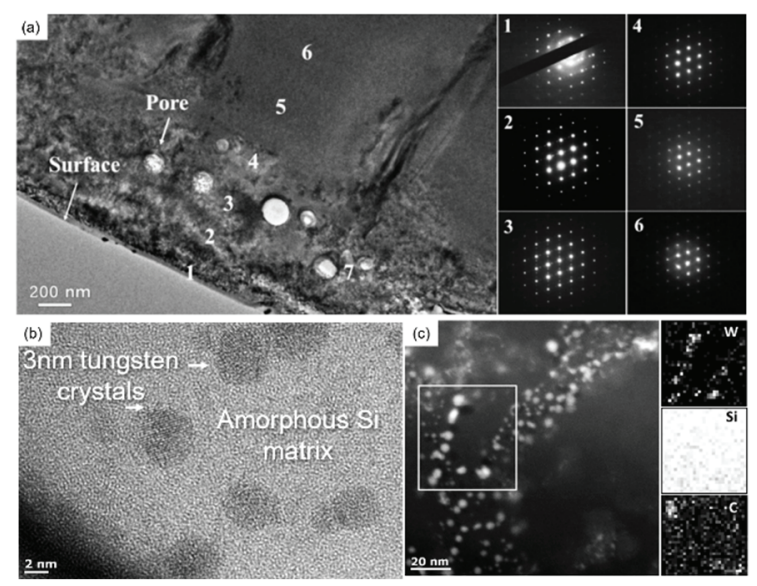

Figure 3 Cross-sectional TEM images of single crystal silicon revealing (a) extensive nano-scale porosity and sub-recast dislocations/cracks and (b) and (c) nanoscale tool electrode deposits in workpiece ${ }^{7}$

electron microscopy on EDM single crystal silicon ${ }^{7}$, with key results shown in Figure 3.

Several key results arose from this unique study. The single crystal silicon surface is littered with deposits of tool electrode material (tungsten in this case), and the scale of these deposits are as small as 3 $\mathrm{nm}$ in diameter, indicating capturing of liquid or vaporised tool electrode material in the recast layer. In addition, a large amount of sub-micron scale porosity was seen, down to less than $100 \mathrm{~nm}$ diameter.

It was clear based on this that "invisible" porosity/tool material likely play a key role in the deterioration of the properties of the EDM recast layer. Amorphisation, as well as cracking of the single crystal material was also seen and was expected given the high cooling rates expected during EDM. This work in EDM fundamentals in collaboration with Prof. Kunieda began many visits from the UoN group to the Kunieda lab, and this collaboration is ongoing.

The prevalence of cracking in EDM materials is one of the main culprits for their poor mechanical performance, in particular fatigue. The TEM study above elucidated the presence of fine cracks at the sub-micron scale, invisible without highmagnification microscopy, much like the case of porosity. The team sought to investigate a rapid method of eliminating near-surface cracking in EDM materials, namely, high current pulsed electron beam irradiation (HCPEB), which can be applied on complex shaped surfaces for which EDM would likely be the most appropriate machining process. The UoN team has enjoyed a fruitful relationship with the Prof. Akira group at Okayama University since the early 2010s around HCPEB activities ${ }^{8}$, with both universities having this unique equipment. A novel application of HCPEB for remelting and removing EDM surface cracks up to $5 \mu \mathrm{m}$ depth, was

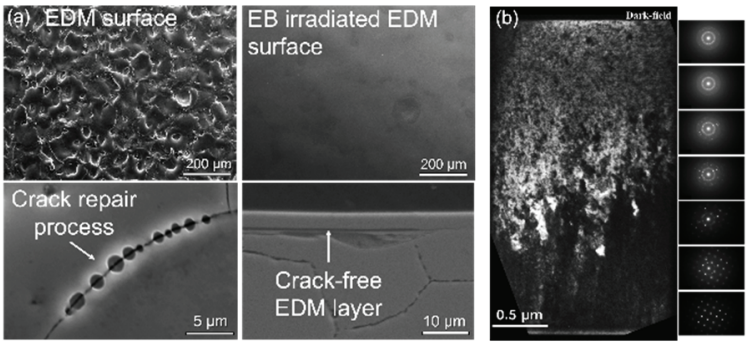

Figure 4 (a) before and after images of a HCPEB treated EDM surface, along with the crack repair process and a cross-sectioned, crack-repaired EDM surface, (b) TEM of cross-section of treated EDM steel, revealing a progressively finer nanostructure 9,10

demonstrated by the UoN team ${ }^{9}$, with images shown in Figure 4.

The typical EDM surface morphology on metals, exemplified here in stainless steel, could also be eliminated during the crack repair process. An incremental crack repair process was revealed, in which surface remelting causes gradual surface tension-based joining of material.

In addition, the team revealed the nanostructure of the remelted EDM layer, in which a columnar structure is followed by a progressively finer nanoscale, dense grain structure towards the top surface, with implications for enhanced mechanical properties via grain boundary strengthening.

\subsection{Coating}

The fundamental machining work described above continues at UoN, with a particular emphasis currently on electrode wear, and new types of dielectrics for emerging applications. Modification of the EDM surface via post-processing as well as chemical modification also builds on prior work with a particular focus on the field of electrical discharge coatings (EDC), in which much progress has been made. The EDM group at UoN has worked on the topic of EDCs since 2014, aiming to build on fundamental work in debris movement to improving surface mechanical properties. UoN has been working in collaboration with Mitsubishi Electric since 2014 to further the understanding and potential applications of the unique process of electrical discharge coating. Our early work sought to reveal the mechanism of formation of thin EDCs - i.e. those that in effect replace the EDM recast layer with a deposited material. Cross-sectional TEM images of a single EDC deposit from a TiC sacrificial electrode, as well as a full coating are shown in Figure 5 (a) and (b) ${ }^{11}$. This work showed that thin EDCs are effectively a composite of substrate material with deposited material, a TiC ceramic in this case, with capillary action causing movement of molten substrate material up and between grains of deposited material. 


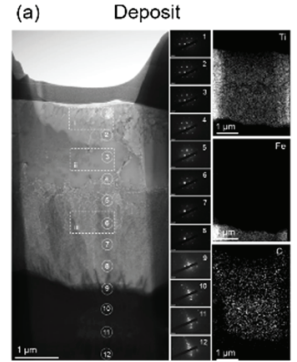

(c)
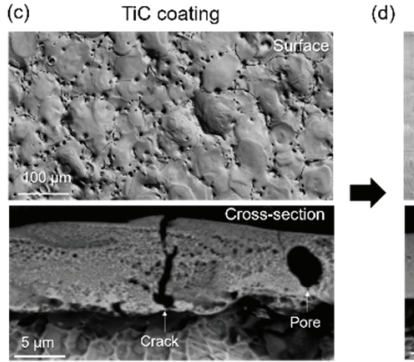

Figure 5 (a) and (b) TEM cross-sections of a thin EDC single deposit and full coating respectively, (c) and (d) Surface and cross-section of a $\mathrm{TiC}$ and $\mathrm{TiC} / \mathrm{Si}$ crackfree coating respectively ${ }^{11}$.

Therefore, thin EDC properties will also include a component from the substrate material.

The group then aimed to address the common problem of cracking associated with deposition of $\mathrm{TiC}$ and other ceramic coatings via EDC.

A combined coating using a $\mathrm{Si}$ sacrificial electrode after an initial coating of $\mathrm{TiC}$ was used to produce a crack and pore free $\mathrm{TiC}$ dominated layer (see Figure 5 (c) and (d) $)^{12}$. It was shown that the relatively low density $\mathrm{Si}$ debris enables expansion of the EDM gap width and reduced impact force associated with the spark, in-turn reducing a lower crack and pore density in the coating. This study is important for the practical implementation of coatings in for example high wear scenarios. The thin EDC project continued to tribological verification of coatings, revealing $\mathrm{TiC}$ based thin coatings can provide good wear properties, although properties are dependent on substrate material ${ }^{13}$, verifying the composite definition of coatings determined previously.

Our collaboration with Mitsubishi continued and progressed with a focus on thick EDCs (or microspark coatings). This work continues to the present. Analogous to our 2014 work in elucidating the formation mechanism of thin EDCs, we sought to reveal in greater detail the development of the more complex thick EDCs. Thick EDCs are coatings in which there is a gradual, net gain of material in a shape reflecting that of the sacrificial electrode. Such electrodes are normally made via pressing, to readily shed material into the discharge gap via mechanical release. A comprehensive study based on observation of individual deposits revealed the nature of thick EDC development ${ }^{14}$. Direct entrapment of unmelted debris in the gap plays a key role in building up of the thick EDC, with further remelting taking place of such material, while already deposited on the coating surface. Powder diameter was also shown to be critical to its ability to deposit, with its cut-off being between 45 and $70 \mu \mathrm{m}$. The dependence of deposition on spark parameters including high and low peak pulse portions of the spark waveform was also elucidated. This work is a foundation to our followon work to further grow the field of thick EDCs. Once again, the group has conducted detailed tribological work to verify and understand the mechanical performance of thick EDCs, in comparison to an alternative laser coating process ${ }^{15}$. Thick EDCs of stellite 31 showed superior wear performance in almost all cases, explained by a higher hardness/elastic modulus ratio, explained by significantly lower grain size of the EDCs as well as presence of porosity. Cross-sections of the comparative coatings, as well as wear and mechanical data are shown in Figure 6.
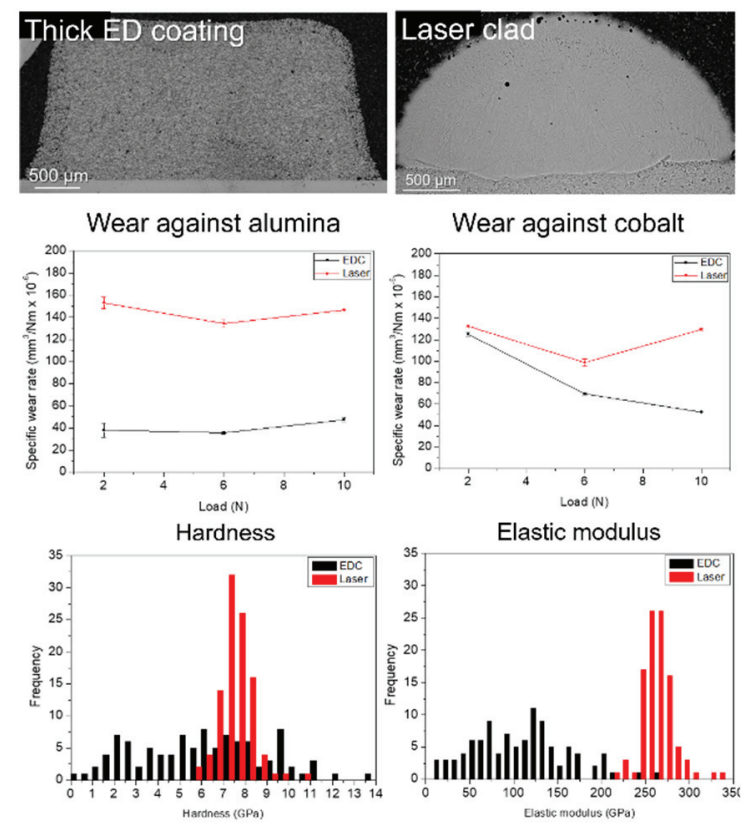

Figure 6 Cross-sections of a thick EDC compared to equivalent laser clad, along with relative wear and mechanical properties ${ }^{15}$.

Work at UoN continues with the grand aim of building a complete picture of the fundamentals of both removal and addition of material by electrical discharge methods. Indeed, the UoN team envision the ED method to be feasible as a simultaneous machining and coating operation, tailored to the 
specific application of the machined part, mitigating the effect of, or enhancing the properties of the EDM surface.

\section{ELECTROCHEMICAL METHODS}

\subsection{Materials}

Material selection in machining processes is dictated by the ultimate application, however simple materials are often desirable to enable phenomenological understanding of removal. An emerging machining technology, EJM research is often performed on stainless steels ${ }^{16,17}$, which respond well to ECM and has multiple applications augmentable with appropriate micromachining.

EJM at Nottingham was born out of collaboration with the University of Tokyo, initially by Kawanaka et al. ${ }^{18}$ through work presented at the $2^{\text {nd }}$ CIRP CSI Conference (Nottingham, 2014). In this study, the effect of machining parameters on the surface generation characteristics in sodium nitrate and sodium chloride electrolytes on 304 stainless steel was reported (Figure 7(a)). Further collaboration between with Tokyo advanced the state-of-the-art in EJM at Nottingham in aerospace alloys. This was demonstrated by Mitchell-Smith et al. ${ }^{19}$ in the study regarding surface structuring of Inconel 718, presented at the INSECT conference (Saarbrüken, 2014). Concurrent collaboration with the University of Bologna investigated the EJM micromachining response of selectively laser hardened steel at different treatments ${ }^{20}$.

Considering the sensitivity of revealed surfaces on the underlying material, Speidel et al. ${ }^{21}$ investigated a range of different $\mathrm{Cu}$ supply conditions, presenting this at ISEM XIX (Bilbao, 2018). Annealing treatments were shown to result in repeatable structuring defined by the underlying microstructure

a)
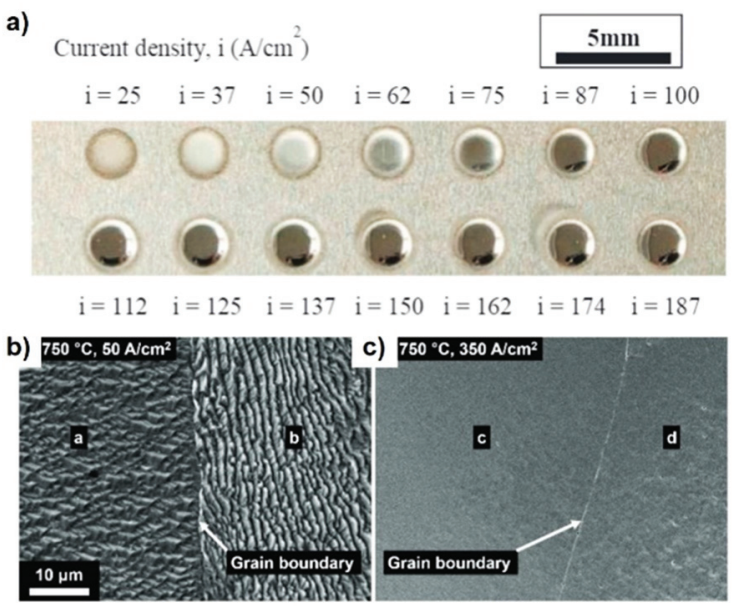

Figure 7: (a) The effect of current density in EJM of stainless stee ${ }^{18}$. (b) $\mathrm{Cu}$ atomic terraces at low current density, and (c) polished at high current density ${ }^{21}$.
(Figure 7(b-c)). In a more complicated dual-phase brass alloy with different treatments, Speidel et al. ${ }^{22}$ demonstrated topography formation mechanisms in multi-phase material EJM, caused by differential dissolution rates.

Subsequently, the research group at UoN has exploited differential dissolution in application-based research, for example in collaboration with the University of Southampton, Walker et al. ${ }^{23}$ enhanced the tribological behaviour of Al-Si alloys used in cylinder liners (Figure 8).

While differential dissolution rates and microstructure-induced surface roughness are often considered undesirable from a surface generation perspective, they can provide an insight into the underlying material. This concept was exploited by Speidel et al. ${ }^{24}$ to spatially resolve crystallographic texture in $\mathrm{Ni}$ and Al-alloys, which can be etched at low current densities in an anisotropic manner. The correlation of revealed etch topographies with the underlying grain orientation was applied as a route through which topography analysis could enable crystallographic texture elucidation.

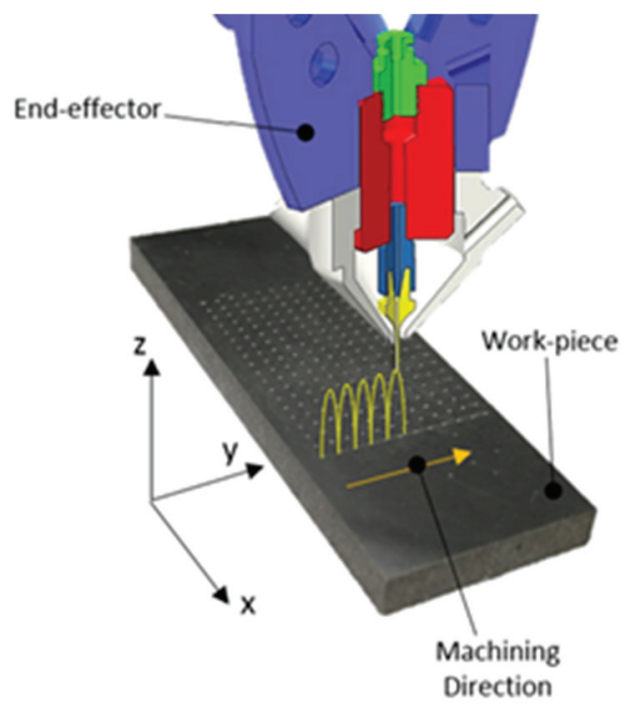

Figure 8: Micro-pits on Al-Si cylinder liner material to adapt tribological properties on contact surfaces ${ }^{23}$.

\subsection{Chemistries}

ECM of Ti-alloys is hampered by the passivating nature of Ti. Passivation layers form rapidly on polarisation in aqueous solutions containing nitratebased electrolytes, disrupting homogeneous material removal. While this is conventionally overcome by applying aggressive chloride anions to electrolytes, the machining response is often still poor ${ }^{25}$. Consequently, studies at UoN were initiated to develop novel electrolyte systems for EJM, based on alternative chemistries, to improve machinability of 
Ti-alloys like Ti-6Al-4V. For example in the work presented at ISEM XVIII (Tokyo, 2016), Speidel et al. ${ }^{26}$ studied how different halide electrolytes and their concentrations could affect the formation of passivation layers in Ti-6Al-4V and this could be exploited to improve machinability of micro-pits. Figure 9(a-b) show the dimensional response upon changing electrolyte chemistry, wherein different electrolytes led to significant differences in the surface topography.

Building on this research, Mitchell-Smith et al. ${ }^{27}$ exploited iodide-doped electrolytes to enhance precision in the machining of Inconel $718 \mathrm{Ni}$-based superalloy. By applying $\mathrm{NaI}$ at varying concentrations, the effective machining threshold could be manipulated to restrict the material removal region, reducing overcut, and increasing feature aspect ratios. The mechanism was determined to arise from the oxidation of iodide to other species such as iodine at the anode, which inhibited material removal and stray current erosion in the outer regions (Figure 9(b)).
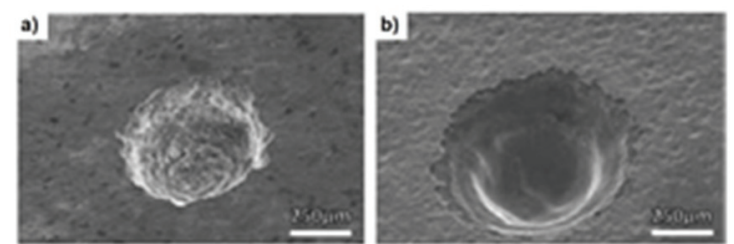

c)

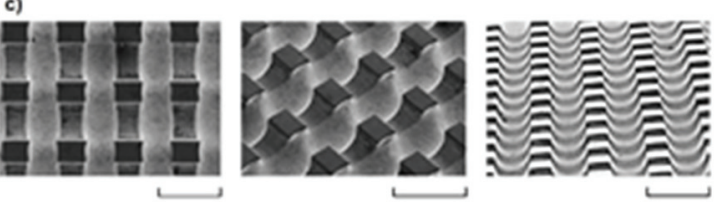

Figure 9: (a-b) Surfaces of micro-pits machined in Ti$6 \mathrm{Al}-4 \mathrm{~V}$ in different electrolyte systems. c) Repeating surface structures machined in Inconel 718 in iodidedoped electrolytes.

The surface oxides present on Ti-alloys lead to interesting phenomena when exposed to translating electrolyte jets. This was explored by Speidel et al. ${ }^{28}$ who applied doped electrolytes to Ti-alloys. Oscillatory behaviour was observed showing periodic voltage fluctuations at constant current parameters where the jet was translated over the workpiece. This was correlated with periodic passive film breakdown and localised dissolution, followed by re-passivation. High current densities $\left(>300 \mathrm{~A} / \mathrm{cm}^{2}\right)$ and lower feed rates were observed to improve machining characteristics, while iodide and bromide dopants were shown to improve aspect ratio and material removal characteristics, respectively.

Given the different and often complex surface responses of different electrolytes in EJM, MitchellSmith et al. ${ }^{29}$ presented at ISEM XIX (2018, Bilbao), the methodology to alter electrolyte chemistries in EJM to change the material removal and dimensional accuracy characteristics of the machined feature in Inconel 718. Recently, progress has been made by machining Ti-alloys in ethylene glycol containing electrolytes, where passivation is suppressed by the removal of water from the inter-electrode gap ${ }^{30}$.

\subsection{Machine Design}

In the field of electrochemical machining, the group at UoN has specifically focused on electrochemical jet machining (EJM) as a promising surface texturing method. Machine tool and process design for EJM have been a major interest with inhouse design and build activities enabling a series of innovations in this area since the completion of the first EJM test rig in 2014.

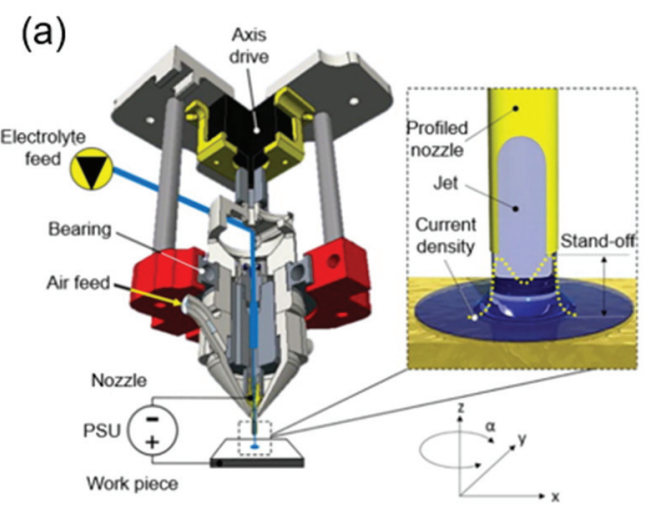

(b)

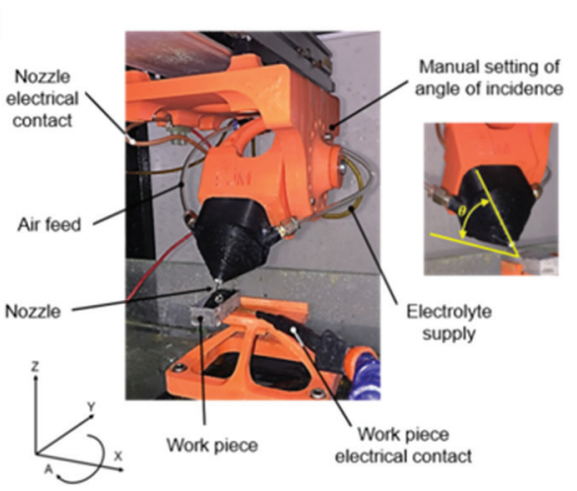

Figure 10 (a) Profiled nozzles and active tooling allowing the manufacture of complicated cut profiles. (b) Angled nozzle holder for EJM.

Several contributions were made in tooling design, resulting in increased flexibility for manufacturing of varied surface textures. Conventionally, the cut profile in EJM is known to have tapered side walls and a rounded apex due to the Gaussian current density distribution resulting from the standard cylindrical nozzle ${ }^{31}$. The modification of nozzle profile $^{32}$ allowed the modulation of material removal 
rate by focusing the current density under the profile features closest to the surface. In this manner, channels with a complicated cross-section could be generated. The introduction of non-axisymmetric nozzles necessitated the development of active tooling (Figure 10(a)) $)^{33}$ to rotate the nozzle about the machine $\mathrm{Z}$-axis and allow the continuous alignment with direction of the machining tool path. The application of complex trajectories while maintaining a uniform channel cross section was made possible. A further method to alter the standard process footprint was explored, which involved tilting the jet at an angle relative to the work piece surface (Figure $10(b))^{34}$. Similarly to nozzle profile modification, this leads to focusing of current flow along the shortest pathways between the nozzle contour and the surface. The incidence angle was also established as an additional factor controlling surface finish in EJM, by defining the current density level at the trailing edge of the jet. The combination of these process design innovations with modified electrolyte chemistry delivered a step change in the achievable precision in $\mathrm{EJM}^{35}$. Reductions of kerf width of up to $40 \%$ were reported making it comparable to nozzle internal diameter.

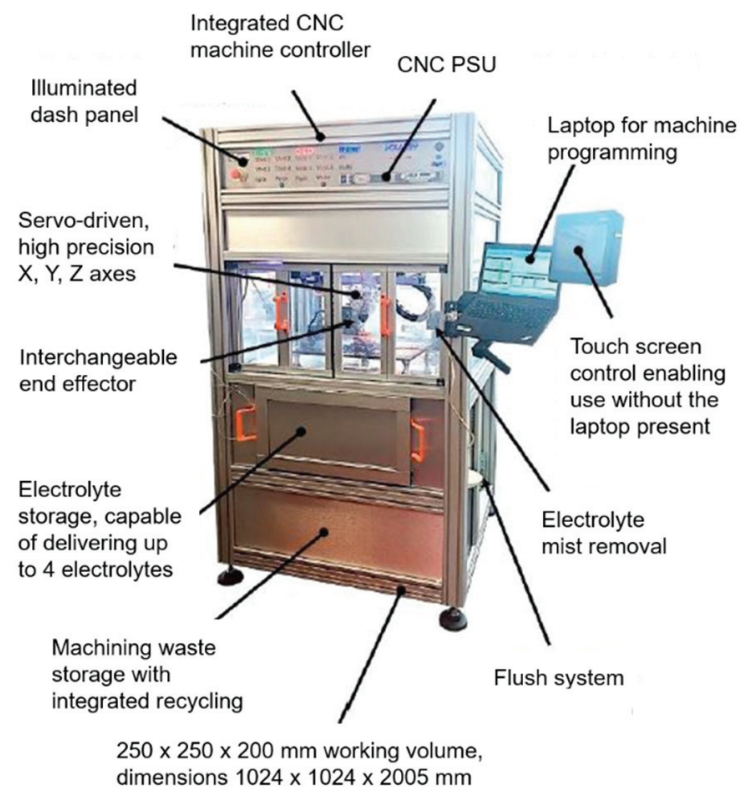

Figure 11 Overview of the EJM machine tool developed at Nottingham.

Building upon these developments and the contributions made by other research groups, a second-generation EJM machine tool prototype (Figure 11) was built which was intended to be more industrially focused and to deliver increased precision, reliability and repeatability. This included a more advanced electrolyte handling system ${ }^{29}$ that allowed rapid change-over and variation of composition of the electrolyte during machining through on-the-fly mixing. Another feature of the new machine tool was the implementation of EJM-specific path planning software and G-code programming ${ }^{36}$ enabling the manufacturing of complicated surface textures on 3dimensional engineering components. The creation of controlled surface roughness gradients on the work piece surface was made possible by the dynamic variation of process parameters as a function of tool path.

\section{CONCLUSIONS AND PERSPECTIVES}

This paper has concisely summarised work in electrical machining at Nottingham over the last 10 years. Much of this has depended upon outstanding collaborations with colleagues around the world and not least of all our friends in Japan. During this time, our team has grown significantly, and we have been able to investigate the response of engineering materials to the key processes of EDM and ECM. Using characterisation techniques, we have been able to provide new insight into material response to understand process behaviour. Building on this foundation we have been able to identify new opportunities for these technologies and propose advances which have been explored further by other researchers.

\section{ACKNOWLEDGEMENTS}

The authors would like to acknowledge the members of our lab past and present who helped undertake this work, Drs Mitchell-Smith and Algodi being notable contributors. The authors would also like to thank the kind support of the Royal Academy of Engineering, the Engineering and Physical Sciences Research Council and Mitsubishi Electric Corporation for continued support.

\section{REFERENCES}

1. Liao, Z. et al. Surface integrity in metal machining Part I: Fundamentals of surface characteristics and formation mechanisms. International Journal of Machine Tools and Manufacture vol. 162103687 (2021).

2. Bannard, J. Fine Hole Drilling Using Electrochemical Machining. in Proceedings of the Nineteenth International Machine Tool Design and Research Conference 503-510 (Macmillan Education UK, 1979). doi:10.1007/978-1-349-81412-1_60.

3. Bannard, J. Effect of surface finish obtained by electrochemical machining on the fatigue life of some titanium alloys. Journal of Applied Electrochemistry 4, 229-234 (1974). 
4. Schumacher, B. M. About the Role of Debris in the Gap During Electrical Discharge Machining. CIRP Annals Manufacturing Technology 39, 197-199 (1990).

5. Luo, Y. F. The dependence of interspace discharge transitivity upon the gap debris in precision electrodischarge machining. Journal of Materials Processing Technology 68, 121-131 (1997).

6. Murray, J., Zdebski, D. \& Clare, A. T. Workpiece debris deposition on tool electrodes and secondary discharge phenomena in micro-EDM. Journal of Materials Processing Technology 212, 1537-1547 (2012).

7. Murray, J. W., Fay, M. W., Kunieda, M. \& Clare, A. T. TEM study on the electrical discharge machined surface of single-crystal silicon. Journal of Materials Processing Technology 213, 801-809 (2013).

8. Okada, A., Okamoto, Y., Clare, A. \& Uno, Y. Fundamental study on releasability of molded rubber from mold tool surface. International Journal of Advanced Manufacturing Technology 70, 1515-1521 (2014).

9. Murray, J. W. \& Clare, A. T. Repair of EDM induced surface cracks by pulsed electron beam irradiation. Journal of Materials Processing Technology 212, 2642-2651 (2012).

10. Murray, J. W., Walker, J. C. \& Clare, A. T. Nanostructures in austenitic steel after EDM and pulsed electron beam irradiation. Surface and Coatings Technology 259, Part, 465-472 (2014).

11. Murray, J. W., Algodi, S. J., Fay, M. W., Brown, P. D. \& Clare, A. T. Formation mechanism of electrical discharge TiC-Fe composite coatings. Journal of Materials Processing Technology 243, 143-151 (2017).

12. Murray, J. W. et al. Defect-free TiC/Si multi-layer electrical discharge coatings . Materials \& Design 155, 352-365 (2018).

13. Algodi, S. J., Murray, J. W., Brown, P. D. \& Clare, A. $\mathrm{T}$. Wear performance of $\mathrm{TiC} / \mathrm{Fe}$ cermet electrical discharge coatings. Wear 402-403, 109-123 (2018).

14. Ahmed, N. et al. Formation of thick electrical discharge coatings. Journal of Materials Processing Technology 285, 116801 (2020).

15. Murray, J. W. et al. Dry-sliding wear and hardness of thick electrical discharge coatings and laser clads. Tribology International 150, (2020).

16. Natsu, W., Ikeda, T. \& Kunieda, M. Generating complicated surface with electrolyte jet machining. Precision Engineering 31, 33-39 (2007).

17. Kawanaka, T. \& Kunieda, M. Mirror-like finishing by electrolyte jet machining. CIRP Annals 64, 237-240 (2015).

18. Kawanaka, T., Kato, S., Kunieda, M., Murray, J. W. \& Clare, A. T. Selective surface texturing using electrolyte jet machining. 2nd CIRP Conference on Surface Integrity (CSI) (2014).

19. Mitchell-smith, J., Murray, J. W., Kunieda, M. \& Clare, A. T. Electrolyte Jet Machining for Surface Texturing of Inconel 718. in 10th International Symposium on Electrochemical Machining Technology (2014).

20. Speidel, A. et al. Surface modification of mild steel using a combination of laser and electrochemical processes. Surface and Coatings Technology 307, 849860 (2016)

21. Speidel, A., Mitchell-Smith, J., Bisterov, I. \& Clare, A.
T. The Dependence of Surface Finish on Material Precondition in Electrochemical Jet Machining. in Procedia CIRP vol. 68 477-482 (Elsevier B.V., 2018).

22. Speidel, A., Mitchell-Smith, J., Bisterov, I. \& Clare, A. $\mathrm{T}$. The importance of microstructure in electrochemical jet processing. Journal of Materials Processing Technology 262, 459-470 (2018).

23. Walker, J. C., Kamps, T. J., Lam, J. W., Mitchell-Smith, J. \& Clare, A. T. Tribological behaviour of an electrochemical jet machined textured Al-Si automotive cylinder liner material. Wear 376-377, 1611-1621 (2017).

24. Speidel, A. et al. Crystallographic texture can be rapidly determined by electrochemical surface analytics. Acta Materialia 159, 89-101 (2018).

25. Liu, W. et al. Effect of Anodic Behavior on Electrochemical Machining of TB6 Titanium Alloy. Electrochimica Acta 233, 190-200 (2017).

26. Speidel, A., Mitchell-Smith, J., Walsh, D. A., Hirsch, M. \& Clare, A. Electrolyte Jet Machining of Titanium Alloys Using Novel Electrolyte Solutions. Procedia CIRP 42, 367-372 (2016).

27. Mitchell-Smith, J., Speidel, A. \& Clare, A. T. Transitory electrochemical masking for precision jet processing techniques. Journal of Manufacturing Processes 31, 273-285 (2018).

28. Speidel, A., Mitchell-Smith, J., Bisterov, I. \& Clare, A. T. Oscillatory behaviour in the electrochemical jet processing of titanium. Journal of Materials Processing Technology 273, 116264 (2019).

29. Mitchell-Smith, J., Speidel, A., Bisterov, I. \& Clare, A. T. Electrolyte Multiplexing in Electrochemical Jet Processing. Procedia CIRP 68, 483-487 (2018).

30. Liu, W., Luo, Z. \& Kunieda, M. Electrolyte jet machining of Ti1023 titanium alloy using $\mathrm{NaCl}$ ethylene glycol-based electrolyte. Journal of Materials Processing Technology 283, 116731 (2020).

31. Yoneda, K. \& Kunieda, M. Numerical Analysis of Cross Sectional Shape of Micro-Indents Formed by the Electrochemical Jet Machining(ECJM). Journal of The Japan Society of Electrical Machining Engineers 29, 18 (1995).

32. Mitchell-Smith, J., Speidel, A., Gaskell, J. \& Clare, A. T. Energy distribution modulation by mechanical design for electrochemical jet processing techniques. International Journal of Machine Tools and Manufacture 122, 32-46 (2017).

33. Mitchell-Smith, J., Bisterov, I., Speidel, A., Ashcroft, I. \& Clare, A. T. Direct-writing by active tooling in electrochemical jet processing. Manufacturing Letters 19, 15-20 (2019).

34. Mitchell-Smith, J., Speidel, A. \& Clare, A. T. Advancing electrochemical jet methods through manipulation of the angle of address. Journal of Materials Processing Technology 255, 364-372 (2018).

35. Clare, A. T., Speidel, A., Bisterov, I., Jackson-Crisp, A. \& Mitchell-Smith, J. Precision enhanced electrochemical jet processing. CIRP Annals 67, 205208 (2018).

36. Bisterov, I., Mitchell-Smith, J., Speidel, A. \& Clare, A. Specific and Programmable Surface Structuring by Electrochemical Jet Processing. Procedia CIRP 68, 460-465 (2018). 